\begin{tabular}{|c|c|}
\hline \multirow{3}{*}{ 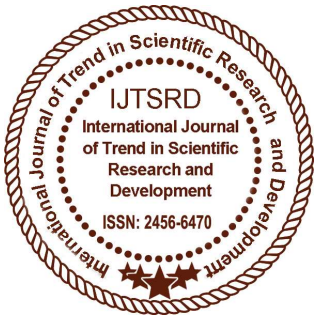 } & $\begin{array}{l}\text { International Journal of Trend in Scientific } \\
\text { Research and Development (IJTSRD) }\end{array}$ \\
\hline & International Open Access Journal \\
\hline & ISSN No: 2456 - 6470 | www.ijtsrd.com | Volume - 2 | Issue - 1 \\
\hline
\end{tabular}

\title{
A Review on Effect of Nano Particle Blended with Diesel Fuel in the Compression Ignition Engine
}

\author{
Abinesh. R \\ B.E Student (Mechanical) \\ Department of Mechanical Engineering, \\ Sri Ramakrishna Engineering College, Coimbatore, \\ Tamil Nadu, India

\section{Jayamurugan. M} \\ B.E Student (Mechanical) \\ Department of Mechanical Engineering, \\ Sri Ramakrishna Engineering College, Coimbatore, \\ Tamil Nadu, India
}

\author{
Abihnav. S \\ B.E Student (Mechanical) \\ Department of Mechanical Engineering, \\ Sri Ramakrishna Engineering College, Coimbatore, \\ Tamil Nadu, India \\ Dr. P. T. Saravana kumar \\ Associate Professor \\ Department of Mechanical Engineering, \\ Sri Ramakrishna Engineering College, Coimbatore, \\ Tamil Nadu, India
}

\section{ABSTRACT}

Diesel engine play important role in the field of commercial transportation and agricultural machinery on account of its superior fuel efficiency. Due to shortage of diesel fuel and its increasing cost as well as hazardous emission emitted by diesel engine, the use of biodiesel and its blends has gained importance over the past two decades due to its environmental and economic benefits. Many countries are evaluating a variety of alternative fuels for use in motor vehicles in an attempt to reduce greenhouse emissions, global warming and to improve the energy security of the nations. Blended fuel is a replacement for the diesel fuel in CI engines due to its significant environmental benefits. The use of blended fuel leads to reduction in particulate matter, hydrocarbon and carbon monoxide emissions that decrease in fuel consumption and the nitrous oxide emission on diesel engine without any modification. The addition of Nano particles with blended diesel fuel increases the efficiency and decreases the emissions. Metal oxides such as alumina, titanium oxide, cerium oxide in the form of nano particles can be used to increase the efficiency as well as to decrease emission. In this review paper work has been done to demonstrate the effect of

various nanoparticles added diesel and biodiesel on performance and emission characteristics of $\mathrm{CI}$ engine.

\section{Introduction:}

A diesel engine has an excellent reputation for its low fuel consumption, reliability and durability characteristics because of its higher brake thermal efficiency due to its high compression ratio and leaner fuel-air mixture. On the other hand diesel engine becomes the main air pollution source in the near future due to its combustion products. Polluted air leads to climate changes and affects plants, animals and human alike. Due to rapid growth of automobiles the demand for petroleum products raises day by day which is expected to rise to more than 240 million metric tonnes by 2021-22, which will further increase to around 465 million metric tonnes by 2031-32. However, the rapid depletion of petroleum products and the stringent regulations lay down by the government to engine manufacturers and consumers to follow the emission norms to save the environment from diesel engine pollution have triggered many researchers to identify renewable alternative fuels for 
diesel engine performance and good emission control. In this regard, biodiesel derived from various vegetable oils such as karanja, jatropha, soybean, palm, neem etc. considered as potential alternative fuel for diesel engine.

Application of nanoscale energetic metal particle additives in li-quid fuel is an interesting concept yet unexplored to its full poten-tial. Such formulated nanofuels offer: shortened ignition delay, decreased burn times and rapid oxidation which leads to complete combustion. Overall calorific value of the liquid fuel in-creases due to higher energy density of metal particles, eventually improving the performance of engine by boosting power output. The study of evaporation rate and ignition probability plays an important role in determining two critical properties: ignition de-lay and ignition temperature which characterizes the performance of a diesel engine and are also instrumental in curtailing emissions. Reports have shown that fuels blended with nanoparticles of aluminum, boron or carbon particles enhance ignition probability at lower temperatures as compared to diesel and initiate combus-tion thereby reducing ignition delay. A crucial phenomenon involved in improving the combustion rate of the nanoparticle.

The direct usage of vegetable oil in diesel engine is restricted because of their high viscosity, poor atomization, incomplete combustion and carbon deposition on the fuel injectors. The use vegetable oil in lower blend concentration with diesel results in engine performance and emission close to neat diesel, but with higher blend concentration performance and emission much inferior compare to neat diesel because of increase in viscosity. The viscosity of vegetable oil reduced by the process of transesterification by converting vegetable oil into methyl ester or ethyl ester known as biodiesel. The considerable work has been carried out by many researchers on performance and emission characteristics of diesel engine with biodiesel and its blends and showed significant improvement in engine performance and reduction in emission of $\mathrm{CO}, \mathrm{HC}$ and smoke, but NOx emission was higher with biodiesel and its blends because of their higher oxygen content . The recent advance in nanotechnology gives the way to produce energetic nanoparticles. The addition nanoadditives in base fuel improve thermo physical properties of fuel such as high surface area to volume, thermal conductivity and mass diffusivity. The use of nanoparticles as additive will act as liquid fuel catalyst and there by enhance the combustion characteristics of engine which will improve engine performance and reduce emissions.

\section{NANOPARTICLES: ITS TYPES AND REQUIREMENTS}

Nano-additives are considered as a propitious fuelborne catalyst to improve the fuel properties, owing to their enhanced surface area/volume ratio, quick evaporation and shorter ignition delay characteristics. The size of nanoparticles varies from 1 to $100 \mathrm{~nm}$ [1].

Following are the main requirements of naonoparticles as fuel additive:

1) The nanoparticles act as catalyst should reduce exhaust emission as well as increase the oxidation intensity in the engine and in the particulates filters.

2) It should maintain the typical operational properties of engine.

3) The stability of additive in the fuel must be retained under all operational condition.

The type of nanoparticles is given in table1.

Table 1 Type of Nanoparticles for IC engine application

\begin{tabular}{|c|c|c|}
\hline S. NO. & \multicolumn{2}{|c|}{ TYPE } \\
\hline 1 & Metal based nanoparticles & Aluminum, iron, boron and ferric chloride \\
\hline 2 & Metal oxide nanoparticles & Cerium oxide, alumina, TiO2, MnO, CuO \\
\hline 3 & Magnetic nanofluid particles & Fe3O4 \\
\hline 4 & Carbon nanotube particles & Single walled and multi walled CNT \\
\hline
\end{tabular}




\section{COMBUSTION MECHANISM NANOPARTICLES ADDED FUELS}

Combustion of nanoparticles added fuel occurred in five stages: (i) preheating and ignition stage (ii) classical droplet combustion stage (iii) micrOEXPLOSION STAGE (IV) SURFACTANt flame stage (v) nanoparticle droplet flame stage [8]. In preheating and ignition stage, evaporation of base fuel occurred on the droplet surface and vapor cloud formed surrounding the fuel droplet. The droplet combustion stage is similar to classical burning behavior of single component droplet. In this stage distinct flame envelope formed around the primary droplet and also small amount of nanoparticles ignited and burning nanoparticles rose quickly to form multiple flares which lead to flame disruption. During flame disruption small bubbles are formed inside primary fuel droplets. These bubbles grow in size and eventually merged into single bubble. Formation of bubbles inside primary droplets builds up intense pressure inside primary drop. Due to building up of intense pressure primary fuel droplets swelled and eventually exploded into smaller droplets and nanoparticles aggregates which ignited and burned forming local flames. This phenomenon of sudden fragmentation of primary fuel droplet into smaller droplets is known as micro explosion. This phenomenon of microexplosion first explained by law [9] based on diffusion-limit model. The droplet surface becomes more concentrated with the less volatile, high-boiling-point component, and the droplet interior has a higher concentration of the more volatile, low-boiling-point component. The latter can be heated beyond its local boiling point, leading to an onset of homogenous nucleation and intense internal pressure buildup and thereby causes fragmentation of the primary fuel droplet. At the end of microexplosion stage nearly all liquid fuel consumed and flame become weaker and finally extinguished and leaving behind agglomerates coated with un-burnt nanoparticles.At the end of microexplosion stage, second flame appear around nanoparticles due combustion of surfactant. This stage known as surfactant flame stage and exists only if fuel droplet contain surfactant. The extinction of surfactant flame is followed by ignition of nanoparticles known as nanoparticle droplet flame stage. In this stage oxygen diffuse on the surface of nanoparticles causes oxidation of nanoparticles. Shortly after nanoparticles are ignited. H. tyagi et al. conducted hot plate ignition probability taste to examine ignition properties of aluminium and aluminium oxide nanoparticles added diesel fuel. They concluded that addition of nanoparticles to fuel improve heat transfer properties and hence droplet ignited at much lower temperature than pure diesel. Nanoparticles added fuel shows shortened ignition delay, longer flame sustenance, rapid oxidation and hence complete combustion.

\section{REVIEW OF VARIOUS LITERATURES}

In this section review of various literatures has been presented on effects of adding various nanoadditives in base fuel on performance and emission characteristics of diesel engine.

Metal based nanoadditives are used as combustion catalyst to promote complete combustion and to reduce consumption of fuel and emission for hydrocarbon fuels. Metal based nanoadditives reduce diesel emission in two ways: (i) metals react with water vapor in the exhaust emission to produce highly reactive hydroxyl radicals (ii) metal serve as an oxidation catalyst which oxidize $\mathrm{CO}$ into $\mathrm{CO} 2, \mathrm{HC}$ into $\mathrm{CO} 2$ and water vapor and carbon (soot) into $\mathrm{CO} 2$. The commonly used metal nanoadditives for hydrocarbon fuels are aluminium, iron, boron and ferric chloride.

G.R. Kannan et al. [1] examined effects of $20 \mu \mathrm{mol} / \mathrm{L}$ ferric chloride $(\mathrm{FeCl} 3)$ added to waste cooking palm oil biodiesel on combustion, performance and emission characteristics of single cylinder direct injection CI engine operated at constant speed of 1500 $\mathrm{rpm}$ at different operating conditions. The test results showed that the $\mathrm{FeCl} 3$ added biodiesel resulted in decreased brake specific fuel consumption by $8.6 \%$ while brake thermal efficiency increased by $6.3 \%$ at optimized operating condition of 280 bar injection pressure and 25.5obTDC injection timing. The $\mathrm{FeCl} 3$ added biodiesel showed lower nitric oxide emission (NO) and slightly higher carbon dioxide emission (CO2) as compared to diesel at standard operating condition. Carbon monoxide (CO), total hydrocarbon (THC) and smoke emission of $\mathrm{FeCl} 3$ added biodiesel decreased by $52.6 \%, 26.6 \%$ and $6.9 \%$ respectively compared to biodiesel without $\mathrm{FeCl} 3$ at an optimized operating condition, but NO emission slightly increased by $4.1 \%$ with $\mathrm{FeCl} 3$ added biodiesel compared to without $\mathrm{FeCl} 3$ added biodiesel at optimum operating condition because $\mathrm{FeCl} 3$ present in fuel oxidize nitrogen into nitric oxide during combustion process. At optimum operating condition higher cylinder pressure, heat release rate and shorter 
ignition delay period was observed with $\mathrm{FeCl} 3$ added biodiesel.

Rakhi N. Mehta et al. [2] investigated burning characteristics, engine performance and emission parameters of a single cylinder CI engine using nanofuels which were formulated by adding nanoparticles of aluminium (A1), iron (F1) and boron (B1) in base diesel. These fuels showed reduced ignition delay and improved combustion rates. The brake thermal efficiency increased by $9 \%, 4 \%$ and $2 \%$ for $\mathrm{A} 1, \mathrm{~F} 1$ and $\mathrm{B} 1$ respectively as compared to diesel at maximum loading conditions. At higher load the SFC reduced by $7 \%$ when engine fuelled with $\mathrm{A} 1$ as compared to diesel, while SFC for F1 and B1 was almost same to that of diesel. Volumetric reduction of $25-40 \%$ in $\mathrm{CO}$ emission, $8 \%$ and $4 \%$ in hydrocarbon emission was observed when engine fuelled with A1 and F1 respectively as compared to diesel. The NOX emission marginally increased compare to pure diesel because of increase in burning temperature in the combustion chamber.

The metal oxide nanoadditives used for hydrocarbon fuels are $\mathrm{TiO} 2, \mathrm{ZnO}, \mathrm{MnO}, \mathrm{A} 12 \mathrm{O} 3$ and $\mathrm{CuO}$. The metal based nanoadditives act as oxygen donating catalyst which provide oxygen for oxidation of $\mathrm{CO}$ or absorbs oxygen for the reduction of NOx.

V. Arul Mozhi Selvan et al. [3] evaluated performance and emission characteristics of CI engine by using $25 \mathrm{ppm}$ cerium oxide $(\mathrm{CeO} 2)$ nanoparticles as additive in neat diesel and diesel-methyl ester of castor oil-ethanol blends (D70B10E20). The authors found that the SFC was lower and BTE was higher with addition of $\mathrm{CeO} 2$ in diesel and D70B10E20 blend compare to diesel and D70B10E20 blend. The addition of $\mathrm{CeO} 2$ in diesel and D70B10E20 blend lower emission of $\mathrm{CO}, \mathrm{HC}$ and smoke, while marginally increased NOX emission compare to pure diesel and D70B10E20 blend.

V. Sajith et al. [4] carried out experimental investigation on performance and emission characteristics of single cylinder constant speed diesel engine fuelled with $\mathrm{CeO} 2$ nanoparticles (10 to $20 \mathrm{~nm}$ ) added to jatropha biodiesel with dosing level of $\mathrm{CeO} 2$ vary from 20 to $80 \mathrm{ppm}$. The tests results showed that BTE increased and SFC reduced by adding nanoparticles in biodiesel compare to pure biodiesel. The nanoadditives promote longer and more complete combustion compared to base fuel because $\mathrm{CeO} 2$ act as an oxygen buffer and thus increase efficiency. Also $\mathrm{CeO} 2$ oxidize carbon deposits from the engine leading to efficient operation and reduced fuel consumption. The addition of $\mathrm{CeO} 2$ nanoparticles to biodiesel decreased $\mathrm{CO}, \mathrm{HC}$ and soot emission compare to biodiesel without $\mathrm{CeO} 2$. $\mathrm{CeO} 2$ nanoadditive has the ability to undergo transformation from stoichiometric $\mathrm{CeO} 2(+4)$ valence state to $\mathrm{Ce} 2 \mathrm{O} 3(+3)$ (cerous oxide) via relatively low energy reaction. $\mathrm{CeO} 2$ supplies oxygen for the reduction of $\mathrm{HC}$ as well as soot and converted to $\mathrm{Ce} 2 \mathrm{O} 3$ as per following reactions (a) and (b).

Hydrocarbon combustion: $(2 \mathrm{x}+\mathrm{y}) \mathrm{CeO} 2+\mathrm{CXHY}$ $\rightarrow[(2 \mathrm{x}+\mathrm{y}) 2] \mathrm{Ce} 2 \mathrm{O} 3+\mathrm{X} 2 \mathrm{CO} 2+\mathrm{Y} 2 \mathrm{H} 2 \mathrm{O}$ (a)

Soot burning: $4 \mathrm{CeO} 2+\mathrm{Csoot} \rightarrow 2 \mathrm{Ce} 2 \mathrm{O} 3+\mathrm{CO} 2$ (b)

The average reduction in $\mathrm{HC}$ emission with $\mathrm{CeO} 2$ nanoadditive was 25 to $40 \%$ with dosing level vary from 40 to $80 \mathrm{ppm}$. Ce2O3 formed from the oxidation of $\mathrm{HC}$ and soot remains active and reoxidised to $\mathrm{CeO} 2$ through the reduction of $\mathrm{NO}$ as per reaction (c). Hence emission of $\mathrm{NO}$ reduced with an average reduction of $30 \%$ with dosing level of $80 \mathrm{ppm} \mathrm{CeO} 2$ nanoparticles. $\mathrm{Ce} 2 \mathrm{O} 3+\mathrm{NO} \rightarrow 2 \mathrm{CeO} 2+12 \mathrm{~N} 2$ (c)

M.A. Lenin et al. [5] carried out comparative study on performance and emission characteristics of diesel engine fuelled with $100 \mathrm{mg} / \mathrm{L}$ manganese oxide $(\mathrm{MnO})$ and copper oxide $(\mathrm{CuO})$ nanoparticles added in diesel fuel. The brake thermal efficiency of diesel $+\mathrm{MnO}$ fuel was higher compare to diesel $+\mathrm{CuO}$ and neat diesel for all loads. The brake thermal efficiency for neat diesel and diesel $+\mathrm{CuO}$ fuel was nearly same. The emission of $\mathrm{CO}$ and $\mathrm{NOx}$ for diesel $+\mathrm{MnO}$ fuel was lower compare to neat diesel and diesel $+\mathrm{CuO}$ fuel for all loads. The emission $\mathrm{HC}$ for neat diesel, diesel $+\mathrm{CuO}$ and diesel $+\mathrm{MnO}$ fuels was nearly same for all load conditions.

M. Santhanamuthu et al. [16] evaluated performance and emission characteristics of single cylinder CI engine fuelled with polanga oil and diesel blend with iron oxide nanoparticles doped as additive. The BTE and BSEC for POD-iron oxide nanoparticle blends were on par with that of neat diesel. The $\mathrm{CO}$ emission was within the range of $\pm 5 \%$ of diesel up to $65 \%$ load condition and higher beyond $65 \%$ load condition for POD-iron oxide nanoparticle blends and $\mathrm{HC}$ emission was lesser than neat diesel by $10-20 \%$ for POD-iron oxide nanoparticle blends. NOx emission was lower for POD-iron oxide nanoparticle blends above $80 \%$ load and smoke emission for POD-iron oxide nanoparticle blends reduced by $10-15 \%$ to that of neat diesel up to $80 \%$ load condition. 
T. Shaafi et al. [7] showed the influence of alumina nanoparticles, ethanol and isopropanol blend as additive with diesel-soybean biodiesel blend fuel on combustion, performance and emission characteristics of naturally aspirated diesel engine and results were compared with those of neat diesel. Cylinder pressure and heat release rate were higher with D80SBD15E4S1+alumina fuel blend compare to diesel and B20 fuel at higher load condition. The thermal efficiency increased by $15.8 \%$ and $17.9 \%$ at full load in case of B20 and D80SBD15E4S1+alumina fuel blend respectively compare to pure diesel. The BSFC reduced by $10.60 \%$ and $11.46 \%$ at full load, when engine was fuelled with B20 and D80SBD15E4S1+alumina fuel blend respectively compare to that of pure diesel. The emission of $\mathrm{CO}$ and $\mathrm{UBHC}$ reduced, while NOX emission slightly increased in case of D80SBD15E4S1+alumina fuel blend compare to diesel and B20 fuel.

C. Syed Aalam et al. [8] conducted experimental investigation to evaluate performance, emission and combustion characteristics of single cylinder CRDI system assisted diesel engine using blend of diesel and zizipus jujube methyl ester blended fuel (ZJME25) along with aluminium oxide nanoparticles (AONP) in mass fraction of $25 \mathrm{ppm}$ and $50 \mathrm{ppm}$. There was reduction in BSFC with AONP added ZJME25 fuel compare to diesel and ZJME fuel with maximum reduction of $6 \%$ observed with $50 \mathrm{ppm}$ AONP concentration ZJME fuel. The brake thermal efficiency increased in comparison with diesel fuel with maximum improvement of $2.5 \%$ with $50 \mathrm{ppm}$ AONP concentrated ZJME fuel. Smoke emission reduced by about $15-20 \%$ with AONP added ZJME fuel. The $\mathrm{HC}$ and $\mathrm{CO}$ emission significantly reduced, while NOX emission slightly increased. The heat release rate and cylinder pressure increased with the addition of AONP to biodiesel.

Prabhu L et al. [9] conducted experiment to investigate performance and emission characteristics of CI engine fuelled with blend of diesel and neem oil methyl ester (B20) along with $250 \mathrm{ppm}$ and $500 \mathrm{ppm}$ $\mathrm{TiO} 2$ nanoparticles. The authors reported that brake thermal efficiency increased and brake specific fuel consumption decreased with $\mathrm{TiO} 2$ added biodiesel blend compare pure diesel and biodiesel blend. The emission of $\mathrm{CO}, \mathrm{HC}$ and smoke reduced, while NO emission slightly increased with $\mathrm{TiO} 2$ added biodiesel blend compare pure diesel and biodiesel blend.
C. Syed Aalam et al. [10] investigated effects of 40 ppm and 80 ppm $\mathrm{Al} 2 \mathrm{O} 3$ and $\mathrm{Fe} 3 \mathrm{O} 4$ nanoparticles added 20\% mahua oil methyl ester blend with diesel (MME20) on performance, emission and combustion characteristics of CRDI diesel engine. They reported that specific fuel consumption decreased and brake thermal efficiency increased with $\mathrm{A} 12 \mathrm{O} 3$ and $\mathrm{Fe} 3 \mathrm{O} 4$ nanoparticles added MME20 compare to pure diesel and MME20 with higher reduction in SFC and increment in BTE was with $\mathrm{A} 12 \mathrm{O} 3$ nanoparticle added MME20. Emission of $\mathrm{CO}, \mathrm{HC}$ and smoke reduced with $\mathrm{A} 12 \mathrm{O} 3$ and $\mathrm{Fe} 3 \mathrm{O} 4$ nanoparticles added MME20 compare to pure diesel and MME20 with higher reduction in emission was with $\mathrm{Al} 2 \mathrm{O} 3$ nanoparticle added MME20. But NOX emission was higher for $\mathrm{A} 12 \mathrm{O} 3$ and $\mathrm{Fe} 3 \mathrm{O} 4$ nanoparticles added MME20 compare to pure diesel and MME20. Higher cylinder pressure and heat release rate observed for $\mathrm{Al} 2 \mathrm{O} 3$ nanoparticle added MME20.

J. Sadhik Basha et al. [11] carried out experimental investigation to establish the effects of Carbon Nanotubes (CNT) with the Jatropha Methyl Esters (JME) emulsion fuel on performance, emission and combustion characteristics of a single cylinder constant speed diesel engine. The experimental results showed significant enhancement in the brake thermal efficiency for the CNT blended JME emulsion fuels compare to that of neat JME and JME emulsion fuel. At the full load, the brake thermal efficiency for the JME fuel was $24.80 \%$, whereas it was $26.34 \%$ and $28.45 \%$ for the JME2S5W (93\% Jatropha Methyl Esters $+2 \%$ Surfactant $+5 \%$ Water) and JME2S5W100CNT (93\% Jatropha Methyl Esters + $2 \%$ Surfactant $+5 \%$ Water +100 ppm CNT) fuels respectively. Increase in brake thermal efficiency with CNT blended JME emulsion fuel is due to combined effect of micro explosion and secondary atomization which improve combustion rate.

The research work on organic nanoadditive in the field of CI engine is limited. W.M. Yang et al. [12] evaluated performance and emission characteristics of 4 cylinder diesel engine fuelled with emulsion fuel with $82.4 \%$ diesel, $4 \%$ water and $12.6 \%$ nano-organic additives by volume. The brake thermal efficiency of engine was 5\% higher than pure diesel because of micro-explosion of water droplet contained in emulsion fuel and there was slight reduction in brake power with emulsion fuel compare to diesel because of lower heating value. The BSFC of emulsion fuel was higher than that of diesel fuel. There was also slight reduction in BMEP and IMEP with emulsion 
fuel. The NOX and smoke emission significantly reduced with emulsion fuel compare to that of diesel. There was reduction in $\mathrm{HC}$ and $\mathrm{CO}$ emission with emulsion fuel compare to pure diesel. The ignition delay of emulsion fuel was slightly longer than that of pure diesel.

Magnetic nanofluids are colloidal suspension of magnetic material in liquid medium and they respond to external magnetic field. The most important feature of magnetic nanofluid is their stability which means that particles in the fluid do not agglomerate and phase separate even in the presence of strong magnetic field.

Nasrin Sabet Sarvestany et al. [13] examined the effects $\mathrm{Fe} 3 \mathrm{O} 4$ magnetic nano particles dispersed in the diesel fuel with the concentrations of 0.4 and 0.8 vol\% on performance and emission characteristics of diesel engine. The nanofluid fuel with nanoparticle concentration of $0.4 \mathrm{vol} \%$ showed better combustion characteristics in comparison with that of $0.8 \mathrm{vol} \%$. There was reduction in BSFC values for $0.4 \mathrm{vol} \% \mathrm{NF}$ fuel compare to that of neat diesel, whereas 0.8 vol\%NF fuel shows an enhancement in BSFC values compared to that of neat diesel and $0.4 \mathrm{vol} \%$ fuels. Also experimental results reveled that $\mathrm{NOx}$ and $\mathrm{SO} 2$ emissions reduced, while $\mathrm{CO}$ emission and smoke opacity increased with increasing the dosing level of nanoparticles. The NOx emission reduced because iron oxide nanoparticles absorb oxygen for the reduction of NOX, with the average reductions of around $56 \%$ and $67 \%$ in the cases of $0.4 \mathrm{vol} \% \mathrm{NF}$ and $0.8 \mathrm{vol} \% \mathrm{NF}$ fuels respectively compare to that of neat diesel. The emission of sulfur dioxide decreased around $14 \%$ and $20 \%$ in the cases of $0.4 \mathrm{vol} \% \mathrm{NF}$ and $0.8 \mathrm{vol} \% \mathrm{NF}$ fuels respectively compare to that of neat diesel.

M. Mirzajanzadeh et al. [14] examined effects of adding hybrid nanocatalyst ( $\mathrm{CeO} 2+\mathrm{Multi}$ walled carbon nanotube) in diesel and waste cooking oil methyl ester blends (B5 and B20) on performance and emission characteristics of diesel engine. The hybrid nanocatalyst was added in dosing level of 30, 60 and $90 \mathrm{ppm}$. The engine torque and power increased by adding hybrid nanocatalyst compare to pure blend. The maximum increase in power and torque was $7.81 \%, 4.91 \%$ respectively with B20 (90 ppm) compare to $\mathrm{B} 20$. The $\mathrm{BSFC}$ reduced by adding nanocatalyst in blend with maximum reduction of $4.50 \%$ with B20 (90 ppm) compare to B20. Because of unique oxygen absorption and donation properties of $\mathrm{CeO} 2$ nanoadditive the emission of $\mathrm{CO}, \mathrm{HC}, \mathrm{NOx}$ and soot reduced. The MWCNT acts as support for $\mathrm{CeO} 2$. The maximum reduction in $\mathrm{CO}, \mathrm{HC}, \mathrm{NOx}$ and soot were $18.9 \%, 38.8 \%, 71.4 \%$ and $26.3 \%$, respectively with B20 (90 ppm) compare to neat B20. The MWCNT acts as catalyst to accelerate burning rate which result in decreased ignition delay. The $\mathrm{CeO} 2$ nanoparticles act as oxygen donating catalyst which oxidize $\mathrm{CO}$ into $\mathrm{CO} 2$ and absorb oxygen for reduction of NOx into nitrogen. The activation energy of $\mathrm{CeO} 2$ burn off carbon deposits within the combustion chamber and hence lower $\mathrm{HC}$ and soot emission.

V. Selvan et al [15] studied performance and emission characteristics of VCR engine at optimum compression ration of 19:1 using diesterol (dieselcastor oil biodiesel - ethanol blend) - $\mathrm{CeO} 2$ - CNT blends. They used $\mathrm{CeO} 2$ and $\mathrm{CNT}$ of each 25, 50 and $100 \mathrm{ppm}$ of concentrations added with diesterol blends. The addition of nanoparticles in diesterol blends increased thermal efficiency by $7.5 \%$, reduced $\mathrm{HC}$ and smoke emission by $7.2 \%$ and $47.6 \%$ respectively compare to diesterol blends without nanoparticles.

\section{CONCLUSION}

From the above literature review it has been concluded that

1. The nanoadditives act as combustion catalyst which reduce delay period and promote complete combustion when added to base fuel and hence increase efficiency of engine and lower brake specific fuel consumption.

2. There is reduction in $\mathrm{CO}$ emission with all type nanoparticles except magnetic nanoparticles added to base fuel compare to base fuel without nanoparticles because nanoparticles oxidize $\mathrm{CO}$ into $\mathrm{CO} 2$. With magnetic nanoparticles $\mathrm{CO}$ emission increase compare to base fuel without nanoparticles.

3. The activation energy of nanoparticles burn off carbon deposits within combustion chamber which lower $\mathrm{HC}$ and smoke emission.

4. With nanoparticle added emulsion fuel because of micro-explosion and secondary atomization phenomenon the performance of engine improved and reduced emission compare to emulsion fuel without nanoparticles.

5. Some researchers found that addition of nanoparticles to diesel and biodiesel lower NOx emission, while some researchers found that addition 
of nanoparticles to diesel and biodiesel increase NOx. emission.

\section{REFERENCES}

[1] G.R. Kannan, R. Karvembu and R. Anand, "Effect of metal based additive on performance emission and combustion characteristics of diesel engine fuelled with biodiesel", Applied Energy, vol. 88, pp. 36943703, May 2011.

[2] Rakhi N. Mehta, Mousumi Chakraborty and Parimal A. Parikh, "Nanofuels: combustion, engine performance and emission", Fuel, vol. 120, pp. 91-97, December 2013.

[3] V. Arul Mozhi Selvan, R.B. Anand and M. Udayakumar, "Effects of cerium oxide nanoparticle addition in diesel and diesel-biodiesel-ethanol blends on the performance and emission characteristics of a CI engine", ARPN Journal of Engineering and Applied Sciences, vol. 4, pp. 1-6, September 2009.

[4] Sajith, C.B. Shobhan and G.P. Peterson, "Experimental investigations on the effects of cerium oxide nanoparticles fuel additives on biodiesel", Advances in Mechanical Engineering, vol. 36, pp. 1$16,2010$.

[5] M.A. Lenin, M.R. Swaminathan and G. Kumaresan, "Performance and emission characteristics of a DI diesel engine with a nanofuel additive", Fuel, vol. 109, pp. 362-365, March 2013.

[6] M. Santhanamuthu, S. Chittibabu, T. Tamizharasan, and T.P. Mani, "Evaluation of CI engine performance fuelled by Diesel-Polanga oil blends doped with iron oxide nanoparticles", International Journal of Chem Tech Research, vol. 6, pp.1299-1308, June 2014.

[7] T. Shaafi, R. Velraj, "Influence of alumina nanoparticles, ethanol and isopropanol blend as additive with diesel-soybean biodiesel blend fuel: combustion, engine performance and emissions", Renewable Energy, vol. 80, pp. 655-663, March 2015.

[8] C. Syed Aalam, C.G. Saravanan and M. Kannan, "Experimental investigation on a CRDI system assisted diesel engine fuelled with aluminium oxide nanoparticles blended biodiesel", Alexandria Engineering Journal, vol. 54, pp. 351-358, April 2015.

[9] Prabhu L, S. Satish Kumar, A. Anderson and K. Rajan, "Investigation on performance and emission analysis of $\mathrm{TiO} 2$ nanoparticle as an additive for biodiesel blends", Journal of Chemical and Pharmaceutical science, issue 7, pp. 408-412, 2015.

[10] C. Syed Aalam, C.G. Saravanan, "Performance enhancement of common rail diesel engine using nanoparticles blended biodiesel", International Research Journal of Engineering and Technology, 2015, 2, 1400-1410.

[11] J. Sadhik Basha and R.B. Anand, "Performance, emission and combustion characteristics of a diesel engine using carbon nanotubes blended jatropha methyl ester emulsions", Alexandria Engineering Journal, vol. 53, pp. 259-273, April 2014.

[12] W.M. Yang, H. An, S.K. Chou, K.J. Chua, B. Mohan, V. Sivasankaralingam, V. Raman, A. Maghbouli, J. Li, "Impact of emulsion fuel with nanoorganic additives on the performance of diesel engine", Applied Energy, vol. 112, pp. 1206-1212, 2013.

[13] Nasrin Sabet Sarvestany, Abdulali Farzad, Ehsan Ebrahimnia-Bajestan and Massoud Mir, "Effects of magnetic nanofluid fuel combustion on the performance and emission characteristics", Journal of Dispersion Science and Technology, vol. 35, pp. 1745-1750, July 2014.

[14] Mehrdad Mirzajanzadeh, Meisam Tabatabaei, Mehdi Ardjmand, Alimorad Rashidi, Barat Ghobadian, Mohammad Barkhi, Mohammad Pazouki, "A novel soluble nano-catalysts in diesel-biodiesel fuel blends to improve diesel engines performance and reduce exhaust emissions", Fuel, vol. 139, pp. 374-382, September 2014.

[15] V. Arul Mozhi Selvan, R.B. Anand, M. Udayakumar, "Effect of cerium oxide nanoparticles and carbon nanotubes as fuel-borne additives in diesterol blends on the performance, combustion and emission characteristics of a variable compression ratio engine", Fuel, vol. 130, pp. 160-167, April 2014. 